\title{
Study of Site Selection for Mountain Forest Wellness Based on GIS and Environmental Health Factors: A Case of Shilongxia Scenic Spot in Tianjin
}

\author{
Chaochen Xue ${ }^{1, a}$, Yonggang $A n^{1,2,3, b}$, Siming Huang ${ }^{1, c}$ \\ ${ }^{1}$ The School of Landscape Architecture, Beijing University of Agriculture \\ ${ }^{2}$ Beijing Laboratory of Urban and Rural Ecological Environment \\ ${ }^{3}$ Beijing Collaborative Innovation Center for Eco-environmental Improvement with Forestry and Fruit Tree \\ a1227724767@qq.com, bWokaixin75@sina.com, c1151664757@qq.com
}

\begin{abstract}
In recent years, with the rapid development of forest health care industry in China, the demand for forest health care base, especially the construction of mountain forest health care base, has become increasingly urgent. Based on the spatial analysis function of GIS software and the impact of mountain forest environmental factors on human health, this paper briefly introduces the main site selection requirements and application of mountain forest recreation base, taking Jixian County as an example.
\end{abstract}

Keywords: Mountain forest conservation base; GIS; Environmental hygiene factors; Suitability analysis.

\section{The meaning of mountain forest conservation base}

Forest health has become a new focus of science and public concern. Defining the definition and connotation of forest recuperation resources is of great scientific significance, which is conducive to the effective utilization and development of mountain resources, and is also the necessary basis for a wider range of research.

Mountain forest recuperation base: relying on mountain forest ecosystem, making full use of superior forest landscape features and ecological resources, scientifically playing the health and health functions of forest environmental factors, combining various base activities, including health exercise, outward bound sports, diet, spa, etc., to adjust the physical and mental health and physical function of tourists. A specific area that satisfies the material and spiritual needs of different groups.

\section{Spatial analysis of site selection for mountain forest healthy breeding base based on GIS software}

Shilongxia Scenic Area in Jixian County of Tianjin is a part of Jiugong Mountain Scenic Area in Tianjin. Jiugong Mountain is one of the best preserved green treasure spots in central China, and it is a gene pool of species. Shilongxia is an important part of Shilongxia Scenic Area, and it is a good site selection for mountain forest recreation base.

\subsection{Elevation analysis}

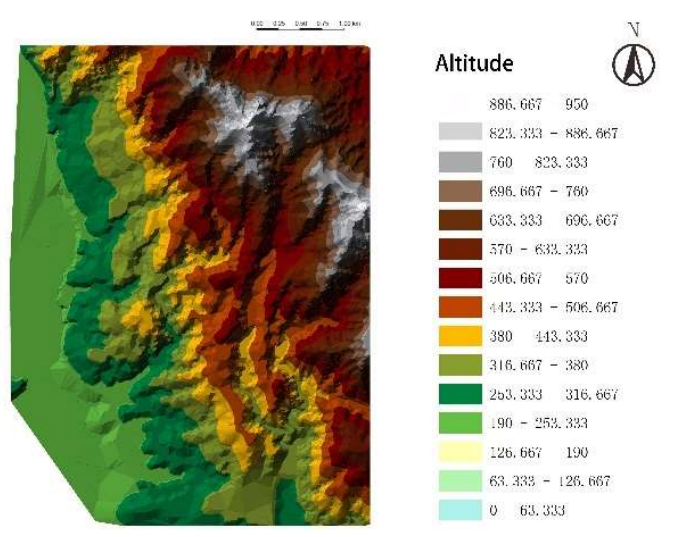

Figure 1. Elevation analysis of Shilong Gorge Scenic Area.

First of all, we should pay attention to the limitation of altitude reaction line. General visitors are not suitable for activities above the plateau reaction line. As can be seen from the following picture, the highest elevation of the 
mountain in the Shilongxia scenic spot is about 900 meters above sea level, which is below the plateau reaction line. Therefore, the entire Shilong Gorge Scenic Area is not affected by the plateau reaction, and can be developed and constructed. In this case, it does not reflect the geographical range of different elevations extracted according to regional height and local height response line.

\subsection{Slope analysis}

Slope is one of the most important factors affecting the location of the forest health care base. Especially in mountainous areas, safety factor is the first element of construction and development, the larger the slope, the more likely to occur safety accidents, including soil erosion, landslides and so on. At the same time, the increase of slope will greatly increase the cost of construction and the degree of construction, seriously affecting the spatial layout of the recuperation base. Therefore, slope analysis is the basis of site selection for mountain forest health care base.

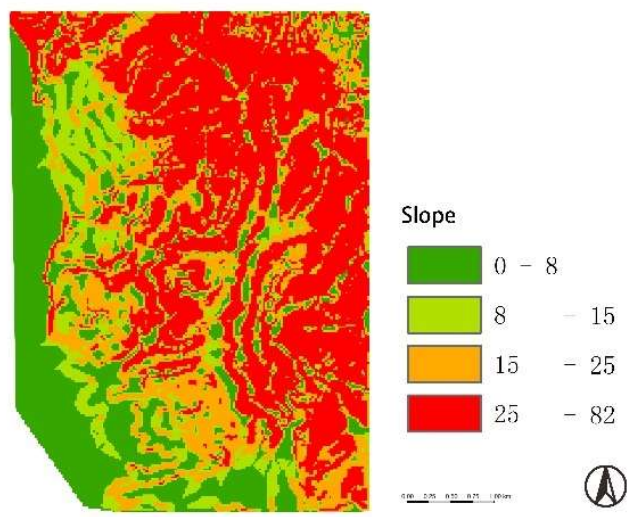

Figure 2. Slope analysis of Shilong Gorge Scenic Area.

In terms of construction standards, the layout is relatively free in small and 8 degree sloping fields. When the slope is between 8 degrees and 15 degrees, the structure of local shape will be limited and the cost will increase. When the slope is greater than 15 degrees, the project construction will be greatly limited, the cost will be greatly increased, and the spatial layout will be greatly affected. The slopes of this area are divided into 4 grades: $0 \sim 8$ degrees, 8 15 degrees, 15 25 degrees, and above 25 degrees. Among them, 0-8 degree is suitable for construction land, 8-15 degree is used to restrict construction land, which is more difficult to develop than 15 degree, and construction land above 25 degree is prohibited. Slope analysis is achieved through DEM model and slope map is obtained.

The results show that the slope of most areas in Shilongxia scenic spot is more than 25 degrees, which is not suitable for large-scale development and construction. The slope of western region is smaller, and the slope of some valleys in central region is also suitable for development and construction. Therefore, it can be concluded that the large-scale construction of Shilongxia mountain forest recuperation base should be in the Western gentle slope region, the central region to set up high-quality recuperation projects, the project site according to the terrain, not a large number of continuous construction.

\subsection{Slope aspect analysis}

Different areas have different slopes and different sunshine hours. According to the geographical location of Shilongxia Scenic Area, there are plenty of illuminated slopes to the South and southeast, which are suitable for building service buildings. Through the analysis of GIS software, we get the analysis of the slope direction of Shilong gorge. Shilong gorge can be divided into eight slope zones: East, Southeast, South, north, West, northwest, southwest and northeast.

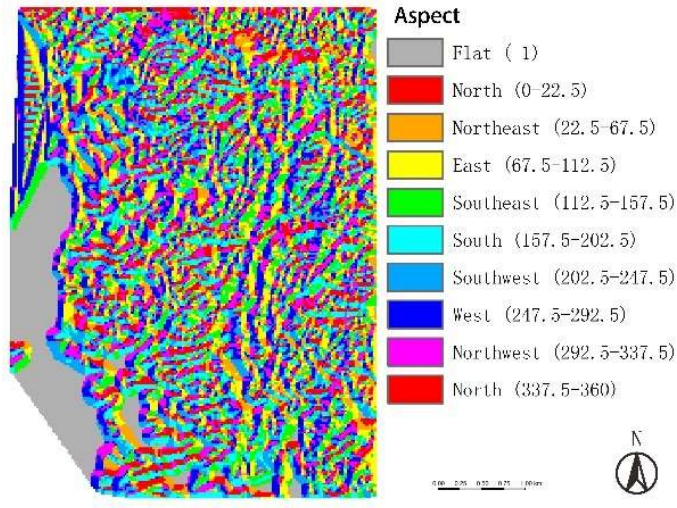

Figure 3. Slope aspect analysis of Shilong gorge area.

Among them, East, West and South are the best directions for the South and the southeast. The north is to restrict construction land. The results show that the slope orientation of the whole scenic area is relatively uniform, and the slope direction area can be built. The center and southeast direction are suitable for construction, and the south direction is roughly the same as the construction slope.

\subsection{General analysis of suitable land use}

Based on the spatial analysis of mountain area by GIS, the suitable construction area of Shilongxia mountain forest recuperation base project is obtained by synthesizing the analysis of elevation, gradient and direction of hill.

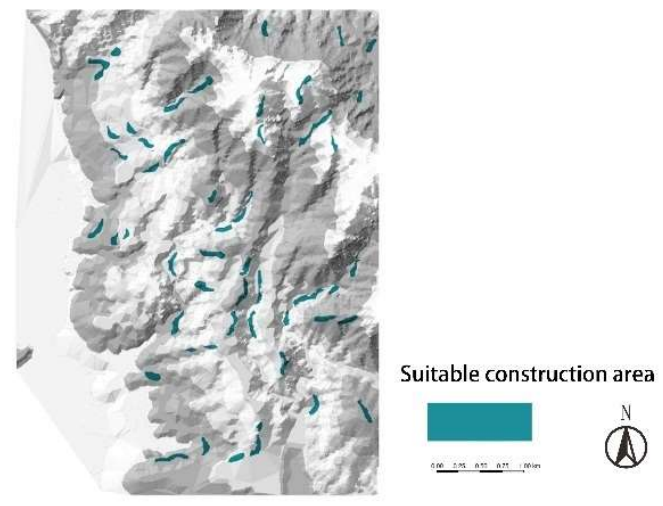

Figure 4. Land for construction in Shilong Gorge Scenic Area. 


\section{Site evaluation of mountain forest conservation base}

In addition to the basic analysis of mountain space by GIS software, another major factor affecting the construction of the base is the construction of environmental factors on the recreational environment.

\subsection{Air anion}

Negative air ions have many functions, including sterilization, reducing dust and clean air. Air is very beneficial to human health, and is very conducive to sleep, lung function, hematopoietic function and other physiological indicators of health. Its concentration level has become an indicator of local air cleanliness.

Forest is an environment that creates good air negative ions. Therefore, the location of environmental forest health care needs to consider the content of negative oxygen ions in air. Water in forests has a significant effect on the level of air negative ions. Specifically, the effect of different water states on the concentration of negative ions is significant. Dynamic water produces more negative air ions than static water. For example, waterfall in dynamic water produces more negative ions than falling, and decreases more than flow. At the same time, the water level is also related to the level of negative ions.

Therefore, the forest waterfall area is generally the area with the highest concentration of negative ions in the air, which is the core area of forest conservation. It is suitable for setting up negative ion breathing area, forest bathing place, forest hospital and other medical and health care places. It is of great practical significance to grasp the distribution of negative ions in the air of forest recuperation area comprehensively and accurately for rational planning of forest recuperation area.

\subsection{Plant essence}

According to the data, there is a positive correlation between the concentration of essential gases and the concentration of negative air ions. On the contrary, the higher the concentration of negative air ions, the higher the concentration of the essence.

Therefore, in the site selection of forest recuperation base construction should also try to choose near the water, humidity, anion-rich areas. ${ }^{[4]}$

\subsection{Forest microclimate}

There are many factors of forest microclimate formation, the most important of which are terrain enclosure and vegetation coverage. The benefits of forest microclimate are to reduce light duration and intensity, and to reduce the difference between daily maximum and minimum temperatures. At the same time, the relative humidity is large and the average wind speed is small, which is conducive to the characteristics of health maintenance.

For mountain forest recuperation base, besides small area enclosure and vegetation coverage, the wind sensation brought by microclimate in different structure position of mountain body is very different. At the top of the hill and the intermontane platform, due to the lack of topographic shelter, less static wind, wind speed is larger, the general static wind frequency is $30 \% \sim 45 \%$. In mountainous areas, valley and other terrain coverage areas, the static wind frequency increases greatly, and the static wind frequency is $50 \% \sim 93 \%$. The average daily wind speed is $0.2 \sim 4.5 \mathrm{~m} / \mathrm{s}$. In addition to topographic factors, forest cover is equally important in the same area, and the frequency of static wind in forests is $20-30 \%$ higher than that in forests. The daily mean wind speed is less than $0.4 \sim 2.3 \mathrm{~m} / \mathrm{S} 2$ outside the forest. ${ }^{[5]}$

Therefore, the site selection and construction of mountain forest recuperation base which can create a suitable recuperation environment has a high requirement should be located in mountain areas, such as hillsides and valleys, to avoid building on the top of the hills and mountain platforms. At the same time, the coverage of forest vegetation is also very important.

\subsection{Summer vacation attribute}

Light, temperature, wind and humidity are the main factors that affect human comfort. As far as illumination is concerned, it is mainly affected by the slope and vegetation coverage. The dense surrounding forests receive less illumination, less northward illumination and more southward illumination. Temperature is mainly affected by altitude. The higher the altitude, the lower the temperature. Wind is mainly affected by topography and vegetation coverage. Humidity is related to industry water and forest cover. To sum up, suitable summer resorts need areas with moderate altitude, low light intensity, suitable temperature, moderate humidity, suitable wind speed, near the water body, and abundant trees.

Generally speaking, if the mountain forest recuperation base needs is to have good summer shelter conditions can be summarized as higher altitude near the water body, surrounding dense trees.

\section{Comprehensive evaluation of site selection for mountain forest healthy breeding base}

In summary, there are two major factors affecting the site selection of mountain forest conservation base. First, the special terrain of the mountain area needs to meet the basic conditions for engineering construction. It includes mountain elevation, slope direction and slope based on GIS software analysis. They are the main factors affecting the construction and engineering of the base; the second is to meet the need to create a good environment for health site selection. Including microclimate created by local topography, forest cover, air anions affected by the location of water type, plant essence, light, wind speed, etc. Among them, to meet the requirements of terrain construction is the basic, on this basis, as far as possible to choose the location in line with the health of the environment. Under the comprehensive consideration of the above two aspects and the support of detailed data in all aspects, it is enough to complete the site selection of 
mountain forest Recuperation Base construction.

\section{Acknowledgement}

This project consists of Scientific and Technological Innovation Service Capacity Building-Scientific Research Base Construction-Eco-environmental Function Promotion Collaborative Innovation Center of Forest and Fruit Industry (2011 Collaborative Innovation Center) (Municipal Level), the project code for 2018 (NO.PXM2018_014207_000024 ); Beijing University of Agriculture think tank project; Ecological education function of Beijing forest health care base (NO.5056516010/005).

\section{References}

1. Chen DA. Building design data set, 1995, vol.6.

2. Duan YM, Du SH. Application of GIS technology in mountain planning and design. Planner, 11, 45-48, 2002.

3. $\mathrm{Wu} \mathrm{CC}$. $\mathrm{Wu}$ Chucai anthology. China Forestry Publishing House, 2015.

4. Bo ZY, Wu CC. Preliminary study on the interaction between air negative ions and plant essential gas. Urban forestry in China, 2008 (01): 56-58.

5. Wu CC, Zeng QM, Zhong LS. Study on air negative ion level in Forest Recreation Area. Forestry Science, 2001 (05): 75-81. 